\title{
Thymidine phosphorylase expression in normal, hyperplastic and neoplastic prostates: correlation with tumour associated macrophages, infiltrating lymphocytes, and angiogenesis
}

\author{
E Sivridis*,', A Giatromanolaki', I Papadopoulos², KC Gatter ${ }^{3}$, AL Harris ${ }^{4}$ and MI Koukourakis ${ }^{5}$ \\ 'Department of Pathology, Democritus University of Thrace, Alexandroupolis, Greece; ${ }^{2}$ Department of Urology, Democritus University of Thrace, \\ Alexandroupolis, Greece; ${ }^{3}$ Nuffield Department of Clinical Laboratory Sciences, John Radcliffe Hospital, Oxford OX3 7LJ, UK; ${ }^{4}$ Molecular Oncology \\ Laboratories, Institute of Molecular Medicine, John Radcliffe Hospital, Oxford OX3 9DS, UK; ${ }^{5}$ Department of Radiotherapy/Oncology, Democritus \\ University of Thrace, Alexandroupolis, Greece
}

Thymidine phosphorylase is an angiogenic factor primarily expressed by cancer cells, stromal cells and tumour-associated macrophages in many human malignancies. These different types of thymidine phosphorylase-expressing cells, however, may have a distinct place in the angiogenic process, and this question was addressed in the present study. A series of 20 normal/ hyperplastic prostate glands and 60 prostate carcinomas was investigated by immunohistochemistry, using specific antibodies for thymidine phosphorylase (P-GF.44C), tumour-associated macrophages (CD68), endothelium (CD3I) and prostate specific antigen (ER-PR8). Thymidine phosphorylase expression by normal and hyperplastic epithelial or stromal cells occurred almost exclusively in the context of an intense lymphocytic infiltrate. High thymidine phosphorylase cancer cells and thymidine phosphorylase stromal cells expression was associated with high angiogenesis in prostate carcinomas, and this significant association was extended to include both tumour-associated macrophages and tumour-infiltrating lymphocytes. Thymidine phosphorylase expression and tumour-infiltrating lymphocytes were related inversely with prostate specific antigen reactivity. In conclusion, thymidine phosphorylase is a major angiogenic factor in prostate carcinomas and its up-regulation is likely to occur in the context of a host immune response.

British Journal of Cancer (2002) 86, |465-|47|. DOI: 10.1038/sj/bjc/660028 I www.bjcancer.com

(c) 2002 Cancer Research UK

Keywords: thymidine phosphorylase; tumour-associated macrophages; infiltrating lymphocytes; angiogenesis; prostate specific antigen; prostate carcinoma

Angiogenesis is the formation of new capillaries from a pre-existing vascular network (Folkman, 1985). It occurs as a physiological phenomenon in regeneration and repair, and as a pathological process in the genesis and progression of cancer. Paracrine stimuli, such as thymidine phosphorylase (TP) and vascular endothelial growth factor (VEGF), released from cancer cells, stromal cells and activated macrophages play an important role in the regulation of tumour angiogenesis. Once activated by these stimuli, endothelial cells proliferate, migrate and, eventually, differentiate into functioning capillaries (Pinedo and Slamon, 2000). In prostate carcinomas, as in other tumours, an increased angiogenesis, assessed as microvessel density (MVD), is usually connected with poor prognosis (Hall et al, 1994; Bettencourt et al, 1998; Borre et al, 1998; Offersen et al, 1998; Strohmeyer et al, 2000a,b).

Thymidine phosphorylase is an important angiogenic stimulus in prostate carcinomas and, as would be expected, it is associated with high MVD (Sugamoto et al, 1999; Okada et al, 2001). The molecule, which is also known as platelet-derived endothelial cell

*Correspondence: E Sivridis, Department of Pathology, Democritus University of Thrace, P.O. Box 128, Alexandroupolis 68100, Greece; E-mail: esivrid@med.duth.gr

Received 24 September 200I; revised 14 February 2002; accepted 27 February 2002 growth factor (PD-ECGF), catalyses the reversible phosphorylation of thymidine to thymine and 2-deoxy-D-ribose-1-phosphate (Fox et al, 1995b; Griffiths and Statford, 1997). The mechanism of the angiogenic activity is through generation of free radicals by the metabolic product 2-deoxy-D-ribose which was shown to stimulate endothelial cell migration and new blood vessel formation (Moghaddam et al, 1997; Brown and Bicknell, 1998; Brown et al $2000)$. The free radicals activate expression of VEGF, interleukin8 (IL8) and matrix metalloproteinase-1 (MMP1) (Brown et al, 2000).

The macrophages are highly differentiated cells of the mononuclear macrophage system which, after activation, assume a variety of specific functions, including phagocytosis (Adams and Hamilton, 1984; Elsbach and Weiss, 1988; Klebanoff, 1988), antigen presentation (Auger and Ross, 1992) chemotaxis (Brown and Gallin, 1988) and release of important secretory products. In malignant disease, the process of macrophage activation was connected with an antitumour activity (Lavnikova et al, 1996; Ragnhammar, 1996) and stimulation of angiogenesis (Polverini and Leibovich, 1984; Arras et al, 1998), the latter being mediated through the secretion of extracellular matrix degrading enzymes and several angiogenic cytokines, including the TP/PD-ECGF (Sunderkotter et al, 1994; Leek et al, 2000). Tumour associated macrophages (TAMs) express TP, but recruitment of activated macrophages into the tumour by tumour cells expressing TP may also contribute to angiogenesis. A 
chemotactic response by monocytes/macrophages to TP has been reported (Miyazono and Takaku, 1991).

The present study was undertaken in order to investigate the expression, distribution and the role played by the different types of TP-expressing cells, including TAMs and tumour-infiltrating lymphocytes (TILs), in stimulating angiogenesis in prostate adenocarcinomas. In addition, TP expression was analysed for possible associations with histological grade and PSA expression.

\section{MATERIALS AND METHODS}

Twenty biopsy and autopsy specimens from normal and hyperplastic prostate glands, and sixty surgical specimens of prostate adenocarcinoma were retrieved from the files of the Department of Pathology, Democritus University of Thrace, Greece. The tissues had been fixed in $10 \%$ formol saline and processed through graded alcohols to paraffin wax. Histological diagnosis of prostate cancer was based on haematoxylin and eosin stained sections. The Gleason system (Gleason, 1966) was used for histological grading. A primary and secondary Gleason score ( 1 to 5 ) was determined for every tumour and the combined score (Gleason sum) was then calculated. To obtain sufficient quantities for statistical analysis, the tumours were grouped in three categories: low grade (well differentiated) if the combined Gleason score was 4 or less; intermediate grade (moderately differentiated) if combined Gleason score were 5,6 or $7(3+4$, with a majority of Gleason 3 areas and a small proportion - less than $20 \%$ - of Gleason 4 components); and high grade (poorly differentiated) if the Gleason sum was $7(4+3)$ or above.

\section{Immunohistochemistry}

Immunohistochemistry was performed at $3 \mu \mathrm{m}$ thick formalin-fixed, paraffin-embedded sections with monoclonal antibodies to: angiogenic factor TP, pan-endothelial antigen CD31, TAMs, and prostate specific antigen (PSA). Details are given in Table 1. A standard streptavidin-biotin immunoperoxidase method was used. Endogenous peroxidase activity was blocked by exposure to absolute methanol containing 3\% hydrogen peroxide. Antigen retrieval was achieved by microwave heating. Non-specific background staining was reduced by protein blocking agent. The primary antibodies were applied for $75 \mathrm{~min}$ at room temperature. The sections were then sequentially incubated with: (a) anti-rabbit anti-mouse antibody (Kwik Biotinylated Secondary, Immunon, Shandon, Pittsburgh, PA, USA) for $15 \mathrm{~min}$, and (b) Kwik Streptavidin peroxidase reagent (Immunon, Shandon, Pittsburgh, PA, USA) for $15 \mathrm{~min}$. Antibody reactivity was detected with 3,3'-diaminobenzidine (DAB) as chromogen. The slides were counterstained with Mayer's haematoxylin. Known positive controls were included in each staining run. Omission of the primary antibody and replacement by normal rabbit serum at the same concentration was used as negative controls.

\section{Assessment of TP and TAMs}

TP expression was assessed in epithelial cells (normal, hyperplastic and neoplastic), stromal cells and in tumour-associated macro- phages. The percentage of TP positive epithelial cells, i.e., epithelial cells with strong cytoplasmic and/or nuclear reactivity, was recorded for each case. The median value was used to define cases into groups of high and low TPcc reactivity.

The expression of TP by stromal fibroblasts and smooth muscle cells (TPsc) was recorded in all optical fields. The percentage of optical fields with strong TPsc expression was recorded, and the median value was used to define groups of high and low TPsc reactivity.

The number of tumour-associated macrophages (TAMs) was determined at $\times 400$ magnification. Counting was performed in three tumour areas of high macrophage concentration (hot spot areas). The mean was calculated. Areas of necrosis were excluded from TAMs quantification.

\section{Assessment of lymphocytic infiltration}

The extent of stromal lymphocytic infiltration was assessed on haematoxylin and eosin stained sections. Areas of necrosis were excluded from this evaluation. The percentage of optical fields $(\times 200)$ with a prominent lymphocytic response in the tumour stroma was recorded, forming the lymphocyte infiltration index (LII). The median value was used to define groups of high and low LII.

\section{Assessment of angiogenesis}

Angiogenesis was assessed by microvessel counting in three tumour areas of high vascular density (hot spot areas) at $\times 200$ magnification. Only vessels with a well defined lumen or a linear vessel shape were taken into account. The mean of these vessel counts obtained was the microvessel density (MVD). Using the median MVD as a cut-off point, our cases were grouped into categories of low and high MVD.

\section{Statistical analysis}

Statistical analysis and graphic presentation were performed using the GraphPad Prism 2.01 package (GraphPad, San Diego, CA, USA, www.graphpad.com). The Fisher's exact test or the unpaired two-tailed $t$-test was used for testing relationships between categorical variables as appropriate. A $P$-value $<0.05$ was considered significant.

\section{RESULTS}

\section{Expression of TP in normal and hyperplastic prostates}

Normal and hyperplastic prostatic glands were, by and large, unreactive to P-GF.44C (Figure 1A). However, in areas of intense lymphocytic infiltration both glandular and stromal cell component expressed TP. The expression was strong and mixed nuclear/cytoplasmic (Figure 1B). A similarly strong nuclear/cytoplasmic reactivity was invariably expressed by the normal, inflammatory cell free, epithelium of the adjacent seminal vesicles.

Table I Details of antibodies, dilutions and antigen retrieval methods used in the present study

\begin{tabular}{lllll}
\hline \multirow{2}{*}{$\begin{array}{l}\text { Primary } \\
\text { antibody }\end{array}$} & \multicolumn{2}{c}{ Dilution/incubation antigen } & & \\
\cline { 2 - 3 } & Time & Retrieval & Specificity & Source \\
\hline CD68 & $1: 50\left(75 \mathrm{~min}^{\mathrm{a}}\right)$ & $\mathrm{MW}^{\mathrm{b}}$ & TAMs & Dako, Denmark \\
JC70 (CD3I) & $1: 20\left(75 \mathrm{~min}^{\mathrm{a}}\right)$ & $\mathrm{MW}^{\mathrm{b}}$ & Endothelium & Dako, Denmark \\
ER-PR8 & $1: 50\left(75 \mathrm{~min}^{\mathrm{a}}\right)$ & $\mathrm{MW}^{\mathrm{b}}$ & PSA & Immunon-Shandon, Pittsburgh, PA, USA \\
P-GF.44C & Supernatant $\left(75 \mathrm{~min}^{\mathrm{a}}\right)$ & $\mathrm{MW}$ & TP & K.C. Gatter (Oxford, UK) \\
\hline
\end{tabular}

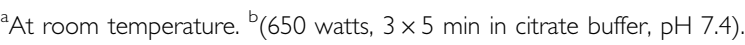


A

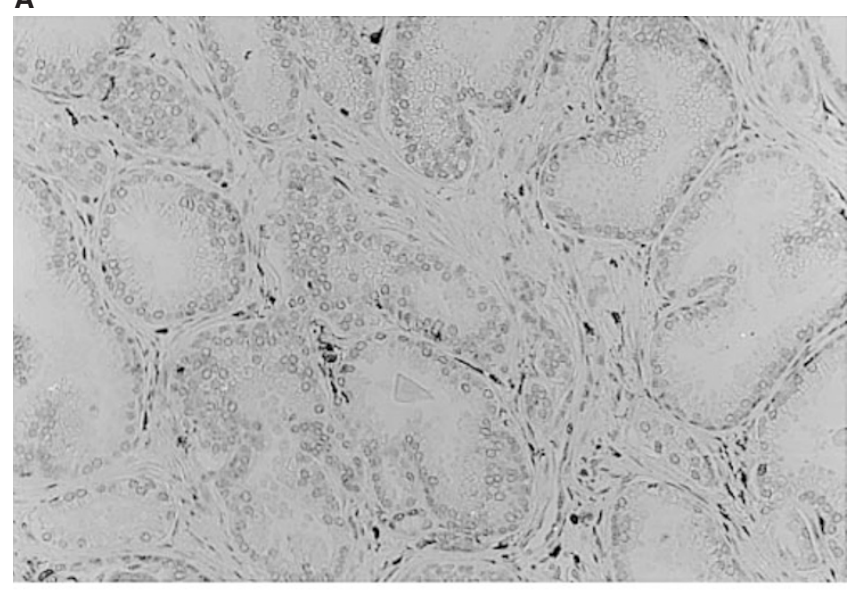

B

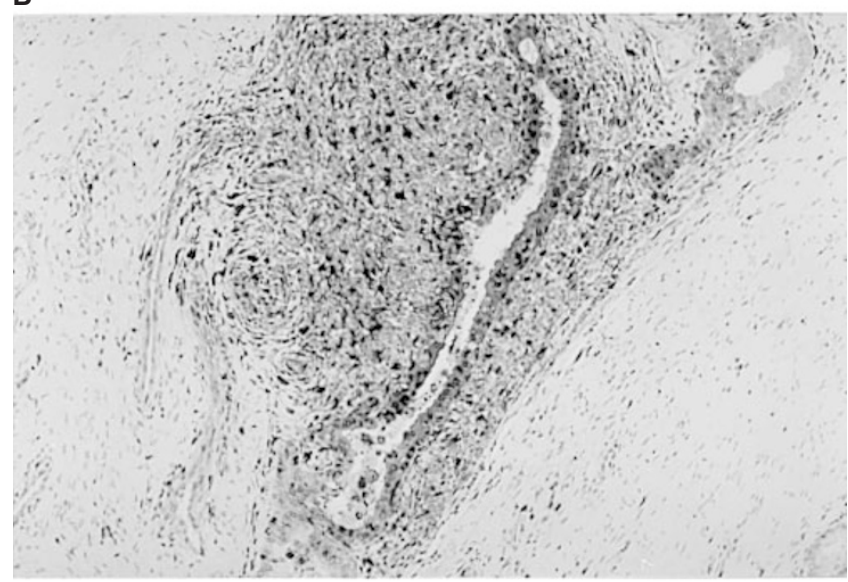

C

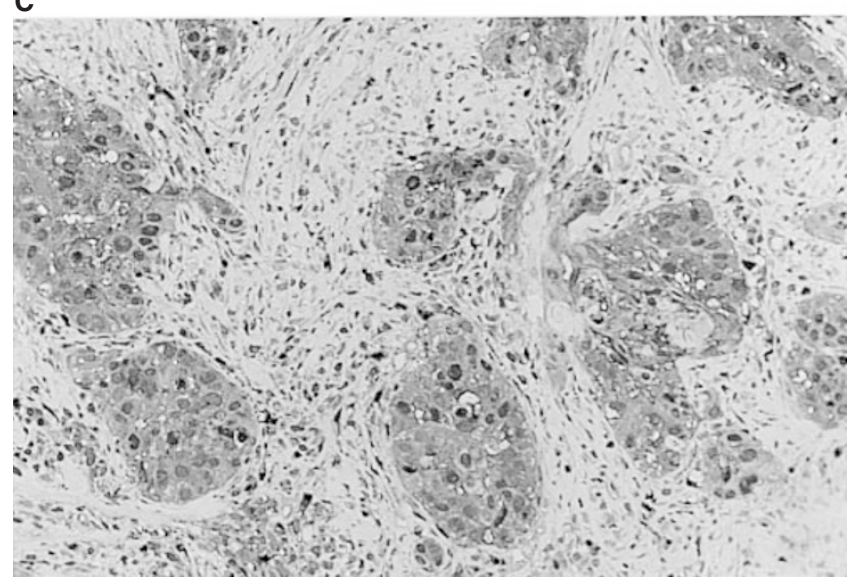

Figure I (A) Normal prostate gland, free of lymphocytic infiltrates, lacking TP expression from ducts, acini and stroma. (B) Normal prostatic acini, densely infiltrared by lymphocytes, exhibiting nuclear and cytoplasmic TP expression by 'epithelial' (basal and secretory) and stromal cells. (C) Prostate carcinoma showing a strong nuclear/cytoplasmic reactivity by tumour and tumour supporting stromal cells.

\section{Expression of TP in prostate carcinomas}

TP was primarily expressed by cancer cells (TPcc), stromal cells (TPsc), of both fibroblastic and smooth muscle origin, endothelial cells (TPec) and in tumour associated macrophages (TAMs). Lymphocytes were also expressing TP but the extent of lymphocytic positivity could not be confidently assessed in the presence of an intense stromal $\mathrm{TP}$ reactivity. In all cases, the pattern of $\mathrm{TP}$ expression was mixed nuclear/cytoplasmic (Figure 1C).

The percentage TPcc ranged from 0 to $90 \%$, with a median of $12.5 \%$. Using this value as a cut off point, 30 cases were of low and 30 cases of high TPcc reactivity.

TPsc reactivity ranged from 0 to $100 \%$ of the optical fields examined. The median value was $20 \%$. A high TPsc expression ( $>20 \%$ ) was noted in 30 of the 60 cases, and was associated with the invariable presence of TP positive TAMs (30 out of 30 cases) and the frequent expression of TPec (12 out of 30 cases $v s 0$ out of 30 cases with low TPsc reactivity) $(P<0.0001)$.

\section{Macrophage and lymphocytic infiltration}

The number of CD68 positive cells enumerated in each case ranged from 5 to 55 per $\times 400$ optical field. The median macrophage number (macrophage index, MФI) was 11 , and the mean value \pm s.d. was $19 \pm 10$. Using the median value, 30 cancer cases were of high and 30 of low MФI. The staining reaction for CD68 was distinctive granular and cytoplasmic.

Lymphocytic infiltration of the tumour supporting stroma was recorded in $0-100 \%$ (median $25 \%$ ) of the $\times 200$ optical fields analysed per specimen (assessment of the whole specimen). The median value was used to define the groups of high (24 cases) and low (36 cases) lymphocyte infiltration index (LII).

\section{Angiogenic correlations}

The median microvessel density (MVD) was 22 (range 7-69). Using this value cases were divided into groups of low (30 patients) and high MVD (30 patients). The staining reaction of endothelial cells was mixed membranous/cytoplasmic.

A high TP reactivity by cancer and endothelial cells was significantly associated with increased angiogenesis in prostate tumours (TPcc $P=0.02$; TPec $P=0.002$ ) (Table 2). High LII was also linked

Table 2 Correlation of MVD with TP expression, macrophage and lymphocyte index

\begin{tabular}{|c|c|c|c|}
\hline & \multicolumn{2}{|c|}{ Microvessel density } & \multirow[b]{2}{*}{$P$-value } \\
\hline & Low & High & \\
\hline \multicolumn{4}{|l|}{ TPcc } \\
\hline Low & 20 & 10 & 0.02 \\
\hline High & 10 & 20 & \\
\hline \multicolumn{4}{|l|}{ TPsc } \\
\hline Low & 19 & 11 & 0.06 \\
\hline High & 11 & 19 & \\
\hline \multicolumn{4}{|l|}{ TPec } \\
\hline No & 29 & 19 & 0.002 \\
\hline Yes & 1 & 11 & \\
\hline \multicolumn{4}{|l|}{ TPcc/TPsc } \\
\hline Low/low & 15 & 6 & 0.04 \\
\hline Low/high & 5 & 4 & \\
\hline High/low & 4 & 5 & \\
\hline High/high & 6 & 15 & \\
\hline \multicolumn{4}{|l|}{ Tpcc/MФ| } \\
\hline Low/low & 14 & 4 & 0.02 \\
\hline Low/high & 6 & 6 & \\
\hline High/low & 5 & 7 & \\
\hline High/high & 5 & 13 & \\
\hline \multicolumn{4}{|l|}{ MФ| } \\
\hline Low & 19 & 11 & 0.06 \\
\hline High & 11 & 19 & \\
\hline \multicolumn{4}{|l|}{ LII } \\
\hline Low & 23 & 13 & 0.01 \\
\hline High & 7 & 17 & \\
\hline
\end{tabular}


with high MVD $(P=0.01)$. The association between TPsc expression and MVD, and between the number of TAMs and MVD was marginal (TPsc $P=0.06$; TAMs $P=0.06$ ).

Using double stratification for TPsc/TPcc, and TPsc/MI a significant angiogenic co-operation between TPsc and TPcc $(P=0.04)$ was shown, and also between TPsc and TAMs $(P=0.02)$ (Table 2 ). Using continuous variable analysis, tumours with high MVD had a significantly higher mean MФI than those having low MVD (mean MPI $22 \pm 12$ vs $16 \pm 8 ; P=0.02$ ).

\section{MФI and TP expression}

There was a significant relationship between TPcc and TPsc expression $(P=0.004$; Table 3$)$. Although prostate carcinomas with high MФI were frequently accompanied with high TPcc and TPsc reactivity, this difference did not reach the level of statistical significance $(P=0.19)$. Using the MФI as a continuous variable, a high MФI was significantly related with TPsc reactivity $(22 \pm 11$ vs $16+9 ; P=0.04$ ), but this was not true in the case of TPcc although there was a similar tendency $(21 \pm 11$ vs $17 \pm 9$; $P=0.10)$. Further, a strong association between high LII and high MФI was noted $(P<0.0001)$. A high LII was also related with high TP expression by cancer $(P=0.06)$ and stromal cells $(P=0.01)$.

\section{Correlation with histological grade and PSA expression}

Out of the 60 cases of prostate cancer, 19 (32\%) did not show any reactivity after staining for PSA and were considered as negative. The remaining showed a varying degree of strong cytoplasmic reactivity (range $25-100 \%$ of cells) and these cases were considered as PSA positive.

Neither TPcc nor TPsc expression was associated with histological grade in prostate carcinomas, but both TPcc and TPsc expression was inversely associated with the expression of PSA $(P=0.05)$ (Table 4). A significant inverse association between LII and PSA expression was also noted $(P=0.02)$. MФI was more frequent in prostate tumours with high histological grade and loss of PSA, but none of these differences was of statistical significance.

\section{DISCUSSION}

Thymidine phosphorylase/platelet-derived endothelial cell growth factor (TP/PD-ECGF) is a potent angiogenic molecule stimulating endothelial cell migration and new blood vessel formation (Moghadam et al, 1995). The enzyme's angiogenic activity has been consistently shown in a variety of human malignancies, despite variations of its principal source of production. Thus, expression

Table 3 Correlation of the histology grade and the PSA expression with TP reactivity, $M \Phi I$ and $L I I$

\begin{tabular}{|c|c|c|c|c|c|c|c|}
\hline & \multicolumn{4}{|c|}{ Grade } & \multicolumn{3}{|c|}{ PSA } \\
\hline & I & 2 & 3 & $P$-value & Negative & Positive & $P$-value \\
\hline \multicolumn{8}{|l|}{$\mathrm{TPcc}$} \\
\hline Low & 9 & 10 & 11 & 0.36 & 6 & 24 & 0.05 \\
\hline High & 14 & 9 & 7 & & 13 & 17 & \\
\hline \multicolumn{8}{|l|}{ TPsc } \\
\hline Low & 12 & 11 & 7 & 0.49 & 6 & 24 & 0.05 \\
\hline High & 11 & 8 & 11 & & 13 & 17 & \\
\hline \multicolumn{8}{|l|}{ МФ| } \\
\hline Low & 12 & 12 & 6 & 0.18 & 7 & 23 & 0.16 \\
\hline High & 11 & 7 & 12 & & 12 & 18 & \\
\hline \multicolumn{8}{|l|}{ LII } \\
\hline Low & 13 & 13 & 10 & 0.66 & 7 & 29 & 0.02 \\
\hline High & 10 & 6 & 8 & & 12 & 12 & \\
\hline
\end{tabular}

Table 4 Association of TP expression with Macrophage and Lymphocyte infiltration index

\begin{tabular}{|c|c|c|c|c|c|c|c|c|c|}
\hline & \multicolumn{3}{|c|}{ Macrophage index } & \multicolumn{3}{|c|}{ Lymphocyte index } & \multicolumn{3}{|c|}{ TPsc } \\
\hline & Low & High & $P$-value & Low & High & $P$-value & Low & High & $P$-value \\
\hline \multicolumn{10}{|l|}{ TPcc } \\
\hline Low & 18 & 12 & 0.19 & 22 & 14 & 0.06 & 21 & 9 & 0.004 \\
\hline High & 10 & 18 & & 8 & 16 & & 9 & 21 & \\
\hline \multicolumn{10}{|l|}{ TPsc } \\
\hline Low & 18 & 12 & 0.19 & 23 & 13 & 0.01 & & & \\
\hline High & 12 & 18 & & 7 & 17 & & & & \\
\hline \multicolumn{10}{|l|}{ LII } \\
\hline Low & 26 & 10 & $<0.0001$ & & & & & & \\
\hline High & 4 & 20 & & & & & & & \\
\hline
\end{tabular}

of TP by cancer cells was shown in carcinomas of the breast (Fox et al, 1995a; Toi et al, 1995), lung (Koukourakis et al, 1997), head and neck (Giatromanolaki et al, 1998) and stomach (Giatromanolaki et al, 2000), whereas a predominant stromal cell TP expression was shown in colorectal (Takebayashi et al, 1996) and endometrial carcinomas (Sivridis et al, 1999), particularly at the invading tumour front. In all cases, however, high TP expression was associated with high angiogenesis, irrespective of the main source of TP production, and this was confirmed by further studies in endometrial and in non-small cell lung tumours, where cancer cells and stromal fibroblasts were independently associated with high angiogenesis (Koukourakis et al, 1998; Sivridis et al, 2001).

Despite our general understanding, the role of TP in prostate cancer remains inadequately studied. Sugamoto et al (1999) indicated that TP levels are higher in prostate carcinomas than in normal prostatic tissues. Okada et al (2001) found that TP is expressed in stromal cells, but not in cancer cells, and that an intense stromal TP reactivity in these tumours was associated with high microvessel density. Okada's immunohistochemical study was performed using two monoclonal antibodies (MoAb), the HCT116 and the P-GF-44C.

The present study was based on the MoAb P-GF-44C. TP was detected extensively (up to $90 \%$ of cells) in the nuclei and the cytoplasm of cancer cells in half of the 60 cases examined. The intensity of staining was strong, and there was a direct association between high TP expression and high angiogenesis in prostate carcinomas. This observation contrasts the results reported by Okada' group (2001). P-GF-44C is a reliable and very sensitive antibody and such a discrepancy is difficult to be explained. Equally difficult is the explanation required for Okuda's finding that normal prostates express TP in $80 \%$ of the cases examined. In our series, normal/ hyperplastic prostate glands and stroma were persistently unreactive to P-GF-44C, and a strong nuclear/cytoplasmic TP expression became only apparent in areas of intense lymphocytic infiltration, probably in the context of a chronic prostatitis. Lymphocytes produce a variety of lymphokines, such as interferons and interleukins, which are potent stimulators of TP expression (Schwartz et al, 1992; Eda et al, 1993; Goto et al, 2001). Certainly, this would explain our finding that extensive lymphocytic infiltration of the prostatic tumour stroma is related with strong TP expression by cancer and stromal cells. The pathway by which lymphocytes, or specific subpopulations of lymphocytes, trigger the expression of TP is not clear, although there are reports implicating CD4 positive cells in tumour angiogenesis (Blotnick et al, 1994) and natural killer (NK) cells in complex interactions with angiogenic factors (Melder et al, 1996). Furthermore, a direct association between lymphocytic and macrophage stromal infiltration was noted. These observations provide strong evidence that upregulation of TP in the normal, hyperplastic and neoplastic prostate tissues occur in the context of a local host immune response against inflammatory or tumour antigens. 
It should be noted in this respect that an intense TP reactivity was consistently detected in normal seminal vesicles, regardless of the presence or otherwise of an inflammatory cell response. The vesicle epithelium, however, is endowed with abundance of mitochondria, a rich rough endoplasmic reticulum and a prominent Golgi apparatus suitable for a vigorous synthetic activity (Nistal et al, 1992). Fructose, in particular, is excessively secreted by the vesicle epithelium (Kise et al, 2000). Catalytic TP-mediated transformation of thymidine to thymine results in 2-deoxyribose-1phosphate production (Brown et al, 2000). Given that ribose is actively involved in fructose metabolism, a regulatory role for TP may be anticipated in this metabolical function (Ozeki et al, 1999; Sawada et al, 2000).

It is of interest, however, that despite the general disparity between our results and those of Okada, this group of investigators did find that TP expression by stromal cells is directly related to increased microvessel density. Furthermore, we found that simultaneous expression of TP by cancer and stromal cells was considerably enhanced the angiogenic activity. This synergistic angiogenic effect of the two cellular elements is probably due to the higher intratumoral TP levels achieved in these cases. Nevertheless, the oxidative stress induced by 2-deoxyribose-1-phosphate promotes secretion of VEGF and interleukin-8 angiogenic molecules (Brown et al, 2000). Both proteins are angiogenic for prostate cancer (Strohmeyer et al, 2000b; Doll et al, 2001; Kim et $a l, 2001)$ and may act synergistically.

Another important observation of the present study is the clear association between the expression of $\mathrm{TP}$ and the accumulation of CD68 positive macrophages (TAMs) in the tumour supporting stroma. This finding, which is in accordance with a previous report of ours on non-small cell lung carcinomas (Koukourakis et al, 1998), reinforces the view for a chemotactic activity of TP on mononuclear cells (Miyazono and Takaku, 1991). TP-mediated macrophage chemotaxia may, therefore, contribute to the angiogenic process, as activated macrophages, apart from producing $\mathrm{TP}$, usually secrete a variety of pro-angiogenic and angiogenic cytokines (Sunderkotter et al, 1994; Ono et al, 1999; White et al, 2001). The angiogenic relevance of an intense macrophage infiltration of the tumour stroma has been shown in a variety of other human tumours including breast (Leek et al, 2000), endometrial (Hashimoto et al, 2000) and lung carcinomas (Takanami et al, 1999), gliomas (Nishie et al, 1999) and malignant melanomas (Torisu et al, 2000).

Nevertheless, the role of macrophages in the angiogenic process is far from clear, as an angio-suppressive effect for TAMs has also been established. Metalloelastase of macrophage origin, has been reported as essential for the production of 'angiostatin', a potent endogenous suppressor of angiogenesis (Dong et al, 1997) and an inhibitor of tumour progression, at least in colorectal carcinomas (Yang et al, 2001). Furthermore, an intense infiltration of TP-expressing macrophages in the tumour stroma was related to an improved survival in patients with colorectal tumours (Saito et al, 2000). Production of the angiogenic inhibitor thrombospon-

\section{REFERENCES}

Adams DO, Hamilton TA (1984) The cell biology of macrophage activation. Annu Rev Immunol 2: 283-318

Arras M, Ito WD, Scholz D, Winkler B, Schaper J, Shaper W (1998) Monocyte activation in angiogenesis and collateral growth in the rabbit hindlimb. J Clin Invest 101: 40-50

Auger MJ, Ross JA (1992) The biology of the macrophage. In The macrophage, Lewis CE, McGee JO’D (eds) pp 23-25. Oxford: Oxford University Press

Bettencourt MC, Bauer JJ, Sesterhenn IA, Connelly RR, Moul JW (1998) CD34 immunohistochemical assessment of angiogenesis as a prognostic marker for prostate cancer recurrence after radical prostatectomy. J Urol 160: $459-465$ din 1 by angiogenic macrophages further underlines the antiangiogenic potential of macrophages (Di-Pietro and Polverini, 1993).

This dual angiogenic/angiosuppressor potential of macrophages emphasises the necessity of identifying specific subpopulations of TAMs, which may have distinct roles in the angiogenic process. The recently reported strong association of high macrophage index with a better post-operative outcome in prostate cancer patients contrasts the postulated 'angiogenic role' of macrophages (Shimura et al, 2000). High angiogenesis is an important variable of poor prognosis in prostate carcinomas, as has been convincingly shown in a large number of studies (Silberman et al, 1997; Bettencourt et al, 1998; Borre et al, 1998; Strohmeyer et al, 2000; Mehta et al, 2001). Specific intratumoural conditions (cytokines released by cancer cells, fibroblasts or even by tumour related lymphocytes) may form a complex code that switches on/off or even reverses the macrophage angiogenic machinery.

Finally, the present study revealed a significant inverse relationship between PSA expression and the expression of the angiogenic factor TP in cancer and stromal cells. Although the loss of PSA expression is rather suggestive of cellular de-differentiation, neither TP nor PSA was related to Gleason's score. This lack of association between TP and histological grade is also a feature of other malignancies, including non small cell lung carcinomas and squamous cell carcinomas of the head and neck (Giatromanolaki et al, 1997, 1998). In a previous study, we reported that PSA was associated with low microvessel density in prostate carcinomas (Papadopoulos et al, 2001). This suppressive effect of PSA on angiogenesis is probably accomplished by a mechanism of converting Lys-plasminogen to biologically active angiostatin-like fragments with an action similar to angiostatin (Heidtmann et al, 1999). However, reduced levels of TP in prostate carcinoma expressing PSA suggests that additional hypotheses are needed in order to explain the direct association of PSA with poor vascularity. Whether suppression of the PSA-gene leads directly to an activation of the angiogenic cascade or whether PSA suppression simply co-exists with the up- or down-regulation of angiogenesis controlling genes requires further investigation.

In conclusion, $\mathrm{TP}$ is a potent angiogenic factor stimulating new blood vessel formation in prostate carcinomas. Tumour angiogenesis is, primarily, induced by angiogenic stimuli released by neoplastic cells, fibroblasts and smooth muscle cells but, in addition, TAMs and infiltrating lymphocytes may be actively involved in the angiogenic process, at least in a subset of carcinomas. Thymidine phosphorylase may be a target for cytotoxic and antiangiogenic therapeutic strategies in prostate tumours.

\section{ACKNOWLEDGEMENTS}

The authors wish to thank Mrs Giannoula Kirmizi for excellent technical assistance.
Blotnick S, Peoples GE, Freeman MR, Eberlein TJ, Klagsbrun M (1994) T lymphocytes synthesize and export heparin-binding epidermal growth factor-like growth factor and basic fibroblast growth factor, mitogens for vascular cells and fibroblasts: differential production and release by CD4+ and CD8+ T cells. Proc Natl Acad Sci USA 91: 2890-2894

Borre M, Offersen BV, Nerstrom B, Overgaard J (1998) Microvessel density predicts survival in prostate cancer patients subjected to watchful waiting. Br J Cancer 78: $940-944$

Brown NS, Bicknell R (1998) Thymidine phosphorylase, 2-deoxy-D-ribose and angiogenesis. Biochem $J$ 334: $1-8$ 
Brown CC, Gallin JI (1988) Chemotactic disorders. In Haematology/oncology clinics of North America. Phagocytic defects, Vol.1 Anormalities outside of the respiratory burst, Curnette JT (ed) pp $162-176$. Philadelphia: W.B.Saunders

Brown NS, Jones A, Fujiyama C, Harris AL, Bicknell R (2000) Thymidine phosphorylase induces carcinoma cell oxidative stress and promotes secretion of angiogenic factors. Cancer Res 60: 6298-6302

Dong Z, Kumar R, Yang X, Fidler IJ (1997) Macrophage-derived metalloelastase is responsible for the generation of angiostatin in Lewis lung carcinoma. Cell 88: $801-810$

Di-Pietro LA, Polverini PJ (1993) Angiogenic macrophages produce the angiogenic inhibitor thrombospondin 1. Am J Pathol 143: 678-584

Doll JA, Reiher FK, Crawford SE, Pins MR, Campbell SC, Bouck NP (2001) Thrombospondin-1, vascular endothelial growth factor and fibroblas growth factor-2 are key functional regulators of angiogenesis in the prostate. Prostate 49: 293-305

Eda H, Fujimoto K, Watanabe S, Ura M, Hino A, Tanaka Y, Wada K, Ishitsuka H (1993) Cytokines induce thymidine phosphorylase expression in tumor cells and make them more susceptible to $5^{\prime}$-deoxy-5-fluorouridine (1993). Cancer Chemother Pharmacol 32: 333-338

Elsbach P, Weiss J (1988) Phagocytic cells: oxygen independent antimicrobial systems. In Inflammation: basic principles and clinical correlates, Gallin JI, Goldstein IM, Snyderman R (eds) pp $341-354$. New York: Raven

Folkman J (1985) Tumor angiogensis. Adv Cancer Res 43: 175-203

Fox SB, Leek RD, Weekes MP, Whitehouse RM, Gatter KC, Harris AL (1995a) Quantitation and prognostic value of breast cancer angiogenesis: comparison of microvessel density, Chalkley count, and computer image analysis. J Pathol 177: 275-283

Fox SB, Moghaddam A, Westwood M, Turley H, Bicknell R, Gatter KC, Harris AL (1995b) Platelet-derived endothelial cell growth factor/ thymidine phosphorylase expression in normal tissues: an immunohistochemical study. J Pathol 176: $183-190$

Gleason DF (1966) Classification of prostate carcinomas (part I). Cancer Chemother Rep 50:125

Giatromanolaki A, Fountzilas G, Koukourakis MI, Arapandoni P, Theologi V, Kakolyris S, Georgoulias V, Harris AL, Gatter KC (1998) Neo-angiogenesi in locally advanced squamous head and neck cancer correlates with thymidine phosphorylase expression and p53 nuclear oncoprotein accumulation. Clin Exp Met 16: 665-672

Giatromanolaki A, Koukourakis MI, Comley M, Kaklamanis L, Turley H, O’Byrne K, Harris AL, Gatter KC (1997) Platelet-derived endothelial cell growth factor (thymidine phosphorylase) expression in lung cancer. $J$ Pathol 181: 196-199

Giatromanolaki A, Koukourakis MI, Stathopoulos GP, Kapsoritakis A, Paspatis G, Kakolyris S, Sivridis E, Georgoulias V, Harris AL, Gatter KC (2000) Angiogenic interactions of vascular endothelial growth factor, of thymidine phosphorylase, and of p53 protein expression in locally advanced gastric cancer. Oncol Res 12: 33-41

Goto H, Kohno K, Sone S, Akiyama S, Kuwano M, Ono M (2001) Interferon gamma-dependent induction of thymidine phosphorylase/platelet-derived endothelial growth factor through gamma-activated sequence-like element in human macrophages. Cancer Res 61: 469-473

Griffiths L, Statford IJ (1997) Platelet-derived endothelial growth factor/ thymidine phosphorylase in tumour growth and response to therapy. $\mathrm{Br}$ J Cancer 76: 689-693

Heidtmann HH, Nettelbeck DM, Mingels A, Jager R, Welker HG, Kontermann RE (1999) Generation of angiostatin-like fragments from plasminogen by prostate-specific antigen. Br J Cancer 81: 1269-1273

Hall MC, Troncoso P, Pollack A, Zhau HY, Zagars GK, Chung LW, von Eschenbach AC (1994) Significance of tumor angiogenesis in clinically localized prostate carcinoma treated with external beam radiotherapy. Urology 44: 869-875

Hashimoto I, Kodama J, Seki N, Hongo A, Miyagi Y, Yoshinouchi M, Kudo T (2000) Macrophage infiltration and angiogenesis in endometrial cancer. Anticancer Res 20: $4853-4856$

Kim SJ, Uehara H, Karashima T, McCarty M, Shih N, Fidler IJ (2001) Expression of interleukin-8 correlates with angiogenesis, tumorigenicity, and metastasis of human prostate cancer cells implanted orthotopically in nude mice. Neoplasia 3: 33-42

Kise H, Nishioka J, Satoh K, Okuno T, Kawamura J, Suzuki K (2000) Measurement of protein $\mathrm{C}$ inhibitor in seminal plasma is useful for detecting agenesis of seminal vesicles or the vas deferens. J Androl 21: 207-212

Klebanoff SJ (1988) Phagocytic cells: products of oxygen metabolism. In Inflammation: basic principles and clinical correlates, Gallin JI, Goldstein IM, Snyderman R (eds) pp 325-340. New York: Raven
Koukourakis MI, Giatromanolaki A, O’Byrne K, Comley M, Whitehouse R, Talbot DC, Gatter KC, Harris AL (1997) Platelet-Derived Endothelial Cell Growth Factor expression correlates with tumor angiogenesis and prognosis in non-small cell lung cancer. Br J Cancer 4: 477-481

Koukourakis MI, Giatromanolaki A, Kakolyris S, O'Byrne KJ, Apostolikas N, Skarlatos J, Gatter KC, Harris AL (1998) Different patterns of stromal and cancer cell thymidine phosphorylase reactivity in non-small-cell lung cancer: impact on tumour neoangiogenesis and survival. Br J Cancer 77: $1696-1703$

Lavnikova N, Prokhorova S, Burdelia L, Lakhotia A, Laskin DL (1996) Mechanisms regulating macrophage-induced nitric oxide production by spontaneously transformed hamster fibroblasts. J Leukoc Biol 60: 473 - 479

Leek RD, Hunt NC, Landers RJ, Lewis CE, Royds JA, Harris AL (2000) Macrophage infiltration is associated with VEGF and VEGFR expression in breast cancer. J Pathol 190: 430 - 436

Mehta R, Kyshtoobayeva A, Kurosaki T, Small EJ, Kim H, Stroup R, McLaren CE, Li KT, Fruehauf JP (2001) Independent association of angiogenesis index with outcome in prostate cancer. Clin Cancer Res 7: 81-88

Melder RJ, Koenig GC, Witwer BP, Safabakhsh N, Munn LL, Jain RK (1996) During angiogenesis, vascular endothelial growth factor and basic fibroblast growth factor regulate natural killer cell adhesion to tumor endothelium. Nat Med 2: 992-997

Moghaddam A, Zhang HT, Fan TP, Hu DE, Lees VC, Turley H, Fox SB Gatter KC, Harris AL, Bicknell R (1995) Thymidine phosphorylase is angiogenic and promotes tumor growth. Proc Natl Acad Sci USA 92: $998-1002$

Moghaddam A, Choudhuri R, Bicknell R (1997) Thymidine phosphorylase/ platelet-derived endothelial cell growth factor: an angiogenic enzyme. In Tumour Angiogenesis, Bicknell R, Lewis CE, Ferrara N (eds) pp $251-$ 260. Oxford: Oxford University Press

Miyazono K, Takaku F (1991) Platelet-derived endothelial cell growth factor: structure and function. Jpn Circ J 55: 1022-1026

Nishie A, Ono M, Shono T, Fukushi J, Otsubo M, Onoue H, Ito Y, Inamura T, Ikezaki K, Fukui M, Iwaki T, Kuwano M (1999) Macrophage infiltration and heme oxygenase-1 expression correlate with angiogenesis in human gliomas. Clin Cancer Res 5: 1107-1113

Nistal M, Santamaria L, Paniagua R (1992) The ampulla of the ductus deferens in man: morphological and ultrastructural aspects. J Anat 180: $97-$ 104

Offersen BV, Borre M, Overgaard J (1998) Immunohistochemical determination of tumor angiogenesis measured by the maximal microvessel density in human prostate cancer. APMIS 106: $463-469$

Okada K, Yokoyama K, Okihara K, Ukimura O, Kojima M, Miki T, Takamatsu $\mathrm{T}$ (2001) Immunohistochemical localization of platelet-derived endothelial cell growth factor expression and its relation to angiogenesis in prostate. Urology 57: 376-381

Ono M, Torisu H, Fukushi J, Nishie A, Kuwano M (1999) Biological implications of macrophage infiltration in human tumor angiogenesis. Cancer Chemother Pharmacol 43(Suppl:): S69-S71

Ozeki T, Mitsui Y, Sugiya H, Furuyama S (1999) Ribose 1,5-bisphosphate regulates rat kidney cortex phosphofructokinase. Comp Biochem Physiol B Biochem Mol Biol 124: 327-332

Papadopoulos I, Sivridis E, Giatromanolaki A, Koukourakis MI (2001) Tumor angiogenesis is associated with MUC1 overexpression and loss of PSA expression in prostate cancer. Clin Cancer Res 7: 1533-1538

Pinedo HM, Slamon DJ (2000) Translational research: the role of VEGF in tumor angiogenesis. Oncologist 5(Suppl 1): 1-2

Polverini PJ, Leibovich SJ (1984) Induction of neovascularization in vivo and endothelial proliferation in vitro by tumor-associated macrophages. Lab Invest 51: $635-642$

Ragnhammar P (1996) Anti-tumoral effect of GM-CSF with or without cytokines and monoclonal antibodies in solid tumors. Med Oncol 13: 167-176

Saito S, Tsuno N, Nagawa H, Sunami E, Zhengxi J, Osada T, Kitayama J, Shibata Y, Tsuruo T, Muto T (2000) Expression of platelet-derived endothelial cell growth factor correlates with good prognosis in patients with colorectal carcinoma. Cancer 88: $42-49$

Sawada M, Mitsui Y, Sugiya H, Furuyama S (2000) Ribose 1,5-bisphosphate is a putative regulator of fructose 6-phosphate/fructose 1,6-bisphosphate cycle in liver. Int J Biochem Cell Biol 32: 447-454

Schwartz EL, Hoffman M, O'Connor CJ, Wadler S (1992) Stimulation of 5fluorouracil metabolic activation by interferon-a in human colon carcinoma cells. Biochem Biophys Res Commun 182: 1232-1239

Shimura S, Yang G, Ebara S, Wheeler TM, Frolov A, Thompson TC (2000) Reduced infiltration of tumor-associated macrophages in human prostate cancer: Association with cancer progression. Cancer Res 60: 5857-5861 
Sivridis E, Giatromanolaki A, Anastasiadis P, Georgiou L, Gatter KC, Harris AL, Bicknell R, Koukourakis MI (2001) Angiogenic co-operation of VEGF and stromal cell TP in endometrial carcinomas. J Pathol (in press)

Sivridis E, Giatromanolaki A, Koukourakis M, Bicknell AL, Harris AL, Gatter KC (1999) Thymidine phosphorylase expression in endometrial carcinomas. Clin Exp Met 17: 445-450

Silberman MA, Partin AW, Veltri RW, Epstein JI (1997) Tumor angiogenesis correlates with progression after radical prostatectomy but not with pathologic stage in Gleason sum 5 to 7 adenocarcinoma of the prostate. Cancer 79: $772-779$

Strohmeyer D, Rossing C, Bauerfeind A, Kaufmann O, Schlechte H, Bartsch G, Loening S (2000b) Vascular endothelial growth factor and its correlation with angiogenesis and p53 expression in prostate cancer. Prostate 45: $216-224$

Strohmeyer D, Rossing C, Strauss F, Bauerfeind A, Kaufmann O, Loening S (2000a) Tumor angiogenesis is associated with progression after radical prostatectomy in $\mathrm{pT} 2 / \mathrm{pT} 3$ prostate cancer. Prostate 42: 26-33

Sugamoto T, Tanji N, Nishio S, Yokoyama M (1999) Expression of plateletderived endothelial cell growth factor in prostatic adenocarcinoma. Oncol Rep 6: $519-522$

Sunderkotter C, Steinbrink K, Goebeler M, Bhardwaj R, Sorg C (1994) Macrophages and angiogenesis. J Leukoc Biol 55: 410-422
Takebayashi Y, Akiyama S, Akiba S, Yamada K, Miyadera K, Sumizawa T, Yamada Y, Akiyama S, Ohi Y (1996) Clinicopathologic and prognostic significance of an angiogenic factor, thymidine phosphorylase, in human colorectal carcinoma. J Natl Cancer Inst 88: 1110-1117

Toi M, Hoshina S, Taniguchi T, Yamamoto Y, Ishitsuka H, Tominaga T (1995) Expression of platelet-derived endothelial cell growth factor/thymidine phosphorylase in human breast cancer. Int J Cancer 64: 79-82

Takanami I, Takeuchi K, Kodaira S (1999) Tumor-associated macrophage infiltration in pulmonary adenocarcinoma: association with angiogenesis and poor prognosis. Oncology 57: 138-142

Torisu H, Ono M, Kiryu H, Furue M, Ohmoto Y, Nakayama J, Nishioka Y, Sone S, Kuwano M (2000) Macrophage infiltration correlates with tumor stage and angiogenesis in human malignant melanoma: possible involvement of TNFalpha and IL-1alpha. Int J Cancer 85: 182-188

White ES, Strom SR, Wys NL, Arenberg DA (2001) Non-small cell lung cancer cells induce monocytes to increase expression of angiogenic activity. J Immunol 166: $7549-7555$

Yang W, Arii S, Gorrin-Rivas MJ, Mori A, Onodera H, Imamura M (2001) Human macrophage metalloelastase gene expression in colorectal carcinoma and its clinicopathologic significance. Cancer 91: 1277-1283 